\title{
Soil carbon dioxide efflux and atmospheric impact in a 10 years Dipterocarpus recovering lowland tropical forest, Peninsular Malaysia
}

\begin{abstract}
Recovering logged-over forest ecosystem increases $\mathrm{CO} 2$ efflux into the atmospheric carbon pool in response of environmental factors to change in soil temperature and moisture. These $\mathrm{CO} 2$ outbursts can have a marked influence on the ecosystem carbon balance and thereby affect the atmospheric carbon pool. The study was conducted in a 10 years logged-over forest of Sungai Menyala forest, Port Dickson, Negeri Sembilan, Malaysia. The measurements of soil $\mathrm{CO} 2$ effluxes were conducted using a continuous open flow chambers technique connected to a multi gas-handling unit and infrared $\mathrm{CO} 2 / \mathrm{H} 2 \mathrm{O}$ gas analyser. The aim of this study is to determine the percentage of $\mathrm{CO} 2$ contributed into the atmosphere from a recovering 10 year logged-over lowland forest. One-way analysis of variance (ANOVA) was used to test the significance correlation between soil $\mathrm{CO} 2$ efflux and environmental variables. Post-hoc comparisons were made using Tukey test ( $\mathrm{p}<0.05)$, and multiple linear regressions were used to determine the impact of environmental factors on soil $\mathrm{CO} 2$ efflux. Soil $\mathrm{CO} 2$ efflux range from 345.6 to $600.4 \mathrm{mg} / \mathrm{mi} 2 / \mathrm{hi} 1$ with the highest efflux in the afternoon attributed to increase in soil temperature and moisture. Higher soil temperature and moisture recorded signify the influential factor. Furthermore, the predictor environmental variables; Soil Organic Carbon (SOC), Total Organic Carbon (TOC), Soil Moisture Content (SMC), Bulk Density, Below Ground Carbon Stock, Total Aboveground Carbon Biomass (TAGB), soil $\mathrm{pH}$, Nitrogen to Carbon ratio account for the spatial and temporal variation in soil $\mathrm{CO} 2$ efflux. These factors attributed to increase in $\mathrm{CO} 2$ efflux into the atmosphere.
\end{abstract}

Keyword: Soil CO2 efflux; Carbon pool; Biomass; Forest ecosystem; Carbon sink 